\title{
PENINGKATAN KEMAMPUAN PENGELASAN SMAW POSISI 2F PEMUDA KELURAHAN KOTO LUAR KECAMATAN PAUH PADANG
}

\author{
Yuli Yetri*, Zulhendri, Yuliarman, Yasmendra Rosa, \\ Rino Sukma, Junaidi, Yusri \\ Jurusan Teknik Mesin, Politeknik Negeri Padang \\ *Email: yuliyetri@pnp.ac.id
}

\begin{abstract}
The community service program carried out by the Mechanical Engineering Department, Padang State Polytechnic lecturer is an activity in order to fulfill the Tridarma of Higher Education for the 2018 budget year. The activity was held in the form of SMAW $2 \mathrm{~F}$ welding improvement training for the youth of Koto Luar, Pauh sub-district, Padang. In this area, there are many high school graduates who have not dared to enter the real workforce because they feel they do not have sufficient skills to join the field workforce. On the other hand, the Koto Luar village is currently developing very fast, because there has been assimilation between migrants and indigenous people. Along with increasing population, of course also followed by the addition of living facilities. To synergize the increase in progress with its human resource capabilities, various knowledge and skills are needed, one of which is the electric welding skills knowledge of SMAW $2 \mathrm{~F}$. Its welding training was attended by 21 Koto Luar youths for 4 days at the Mechanical Engineering department workshop. Expected abilities after training, Koto Luar youths are able to properly weld $2 \mathrm{~F}$ methods according to welding standards, so that later participants are expected to enter the world of welding work. After debriefing the participants can take part in the welding training well, so that they get the SMAW $2 \mathrm{~F}$ welding certificate signed by the director of the Padang State Polytechnic. The welding enhancement training activity of SMAW $2 \mathrm{~F}$ received positive support from the chairman of the Community Empowerment Agency (BPM) and village leaders, because this activity had long been wanted by the community. The Koto Luar community hopes that the training to improve SMAW 2F's welding ability for youth in Pauh Padang sub-district can be carried out continuously, because many young people are interested in SMAW's welding knowledge, the goal is to be able to open entrepreneurs and fill jobs around Lambung Bukit, Koto Luar, and Limau Manis Padang.
\end{abstract}

Keywords: Welding, Skills, SMAW, Training

\begin{abstract}
Abstrak
Program pengabdian kepada masyarakat yang dilaksanakan oleh dosen jurusan Teknik Mesin Politeknik Negeri Padang merupakan kegiatan dalam rangka memenuhi Tridarma Perguruan Tinggi untuk tahun anggaran 2018. Kegiatan ini diadakan dalam bentuk pelatihan peningkatan pengelasan SMAW $2 F$ untuk pemuda kelurahan Koto Luar, kecamatan Pauh kota Padang. Di kelurahan ini banyak tamatan SLTA yang belum berani memasuki dunia kerja real karena merasa belum memiliki keterampilan memadai untuk bergabung dengan tenaga kerja lapangan. Disisi lain kelurahan Koto Luar saat ini berkembang sangat cepat, karena telah terjadi asimilasi antara pendatang dengan penduduk asli. Seiring dengan bertambah penduduk, tentunya juga diikuti pertambahan fasilitas kehidupan. Untuk mensinergiskan pertambahan kemajuan tersebut dengan kemampuan sumber daya manusianya, maka dibutuhkan berbagai pengetahuan dan keterampilan, salah satunya pengetahuan ketrampilan pengelasan listrik SMAW $2 F$. Pelatihan pengelasan listrik SMAW $2 F$ diikuti oleh 21 orang pemuda Koto Luar selama 4 hari di bengkel teknik mesin Politeknik Negeri Padang. Kemampuan yang diharapkan setelah pelatihan, pemuda Koto Luar mampu melakukan pengelasan metoda $2 F$ dengan baik sesuai standar pengelasan, sehingga nantinya peserta diharapkan dapat memasuki dunia kerja pengelasan. Setelahdilakukan pembekalan peserta dapat mengikuti pelatihan pengelasan dengan baik, sehingga mendapatkan sertifikat pengelasan SMAW $2 F$ yang ditanda tangani oleh direktur Politeknik Negeri Padang. Kegiatan pelatihan peningkatan pengelasan SMAW $2 F$ ini mendapat dukungan yang posistip dari ketua BPM dan pimpinan kelurahan, karena kegiatan ini sudah lama diinginkan oleh masyarakat. Masyarakat Koto Luar berharap agar pelatihan peningkatan kemampuan pengelasan SMAW $2 F$ untuk pemuda di kecamatan Pauh Padang dapat dilakukan
\end{abstract}


berkelanjutan, karena banyak pemuda yang berminat dengan pengetahuan pengelasan SMAW ini, tujuannya agar dapat membuka wirausaha dan dapat mengisi lapangan pekerjaan yang ada disekitar Lambung Bukit, Koto Luar, dan Limau Manis Padang.

Kata kunci:Pengelasan, Keterampilan, SMAW, Pelatihan

\section{PENDAHULUAN}

Program pengabdian kepada masyarakat bagi dosen merupakan salah satu program dalam rangka memenuhi Tridharma perguruan tinggiyaitu dharma - Politeknik Negeri Padang tahun anggaran 2018 melakukan pelatihan peningkatan pengelasan SMAW 2F pada pemuda kelurahan Koto luar kecamatan Pauh Kota Padang.

Kelurahan Koto luar merupakan salah satu kelurahan yang berada dalam kecamatan Pauh Kota Padang disamping kelurahan lainnya yaitu: kelurahan Kampung Dalam, Koto Luar, Lambung Bukit, Limau Manis, Limau Manis Selatan, Piai Tangah, dan Pisang. Peta area kecamatan Pauh beserta kelurahannya seperti pada Gambar 1 . Kelurahan Koto Luar memiliki luas daerah 24,86 $\mathrm{KM}^{2}$ dengan jumlah penduduk sebanyak 7.282 orang dengan kode pos 25163.

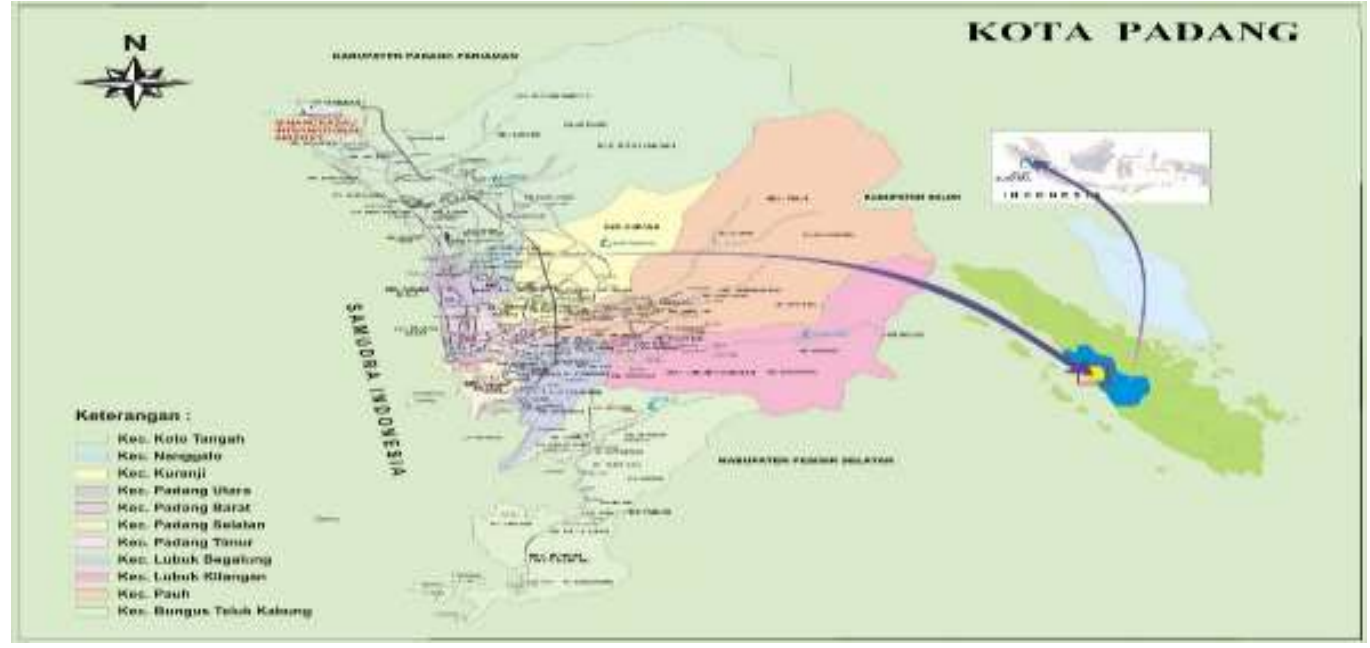

Gambar 1.Peta Kecamatan Pauh

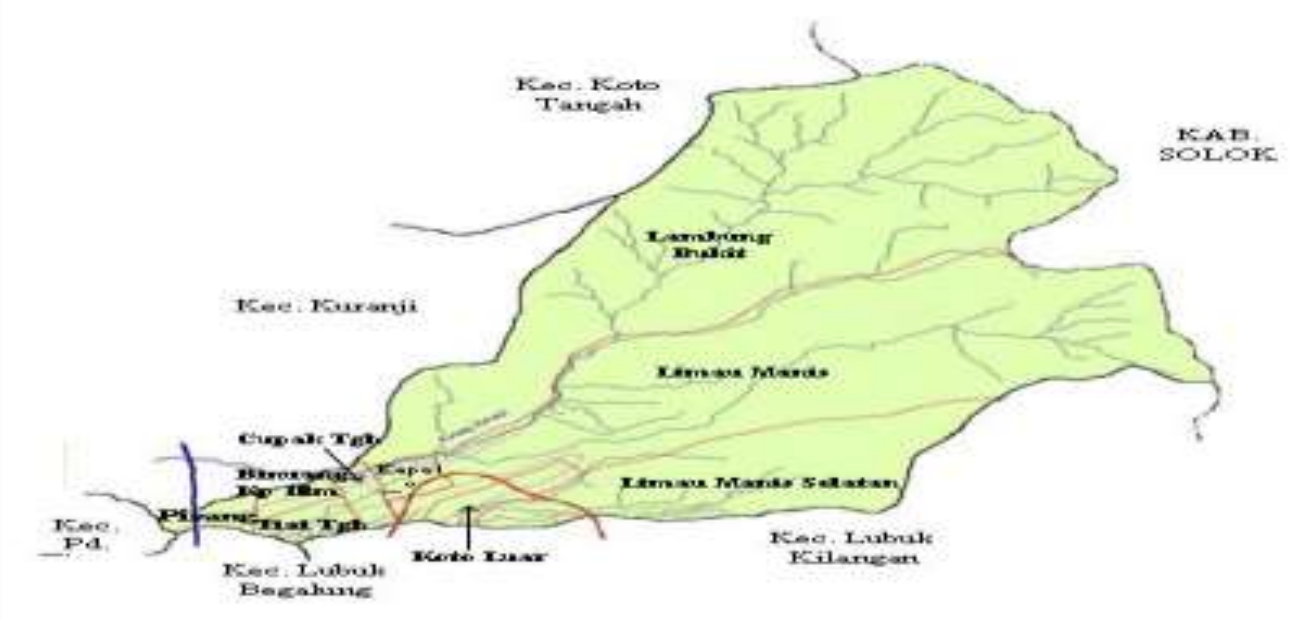


Pada Kelurahan Koto luar berdiri empat instansi besar seperti perguruan tinggi yaitu Univeritas Andalas, Universitas Negeri Padang, Rumah Sakit Universitas Andalas dan Politeknik Negeri Padang. Koto Luar juga memiliki produksi unggulan seperti buah manggis dan buah durian yang manjadi sumber kehidupan masyarakat

Sementarapemudanya masih perlu peningkatan keterampilanagar bisa berperan ditengah masyarakat untuk membangun kelurahannya. Untuk itu kami dari tim pengabdian Politeknik Negeri Padang ingin meningkatkan kemampuan pemudanya dengan memberikan pelatihan keterampilan pengelasan, yang nantinya bisa diaplikasikan dalam bidang pengolahan hasil pertanian.

Pemuda Kelurahan Koto Luar kecamatan Pauh Kota Padang tamatan SLTA belum berani memasuki dunia kerja real (kerja lapangan) karena merasa belum memiliki keterampilan memadai untuk bergabung dengan tenaga kerja lapangan. Kelurahan Koto Luar saat ini berkembang sangat cepat, dengan jumlah penduduk yang selalu bertambah, ada yang tinggal secara permanen dan ada pula yang tinggal sewaktu (selama kuliah/kerja). Seiring dengan bertambah penduduk fasilitas kehidupan juga bertambah. Untuk kemajuan tersebut dibutuhkan berbagai pengetahuan dan keterampilan seperti pengetahuan keterampilan pengelasan listrik SMAW $2 \mathrm{~F}$.

\section{a. Tujuan}

Pengabdian kepada masyarakat pemuda Kelurahan Koto Luar dilaksanakan adalah untuk memenuhi keinginan masyarakat melalui kelurahan dan tokoh masyarakat agar dapat melatih pemuda tentang pengelasan las listrik posisi 2F. Dengan berbekal keterampilan ini, nanti pemuda Koto Luar dapat mengisi peluang kerja yang ada, baik sekitar kelurahan Koto Luar maupun diluar kelurahan Koto luar.

Ketrampilan pengelasan listrik posisi $2 \mathrm{~F}$ ini banyak dibutuhkan saat ini, sehingga keterampilan yang akan diberikan kepada masyarakat merupakanbekal untuk mengisi peluang kerja bagi pemuda Koto Luar. Ketrampilan pengelasan $2 \mathrm{~F}$ ini selain mengisi lowongan kerja yang ada juga dapat membuka lapangan pekerjaan baru bagi yang suka wirausaha, karena pekerjaan pengelasan las listrik posisi $2 \mathrm{~F}$ ini peralatan yang dibutuhkan tidak terlalu mahal sehingga dapat dijangkau oleh ekonomi masyarakat.

\section{b. Manfaat}

Pengabdian kepada masyarakat yang dilaksanakan oleh tim dosen dari Politeknik Negeri Padang bukan hanya untuk memenuhi Tri Dharma Perguruan Tinggi, tetapi merupakan salah satu kesempatan untuk berbagi dengan masyarakat dalam mengatasi persoalan yang ada di masyarakat salah satunya lapangan pekerjaan. Diharapkan setelah mengikuti pelatihan pengelasan SMAW 2F pemuda Kelurahan Koto Luar dapat:

a. Melaksanakan pekerjaan

pengelasan SMAW 2F 
b. Memiliki keberanian untuk bekerja dibidang pengelasan listrik

c. Membuka usaha sendiri atau bergabung dengan bengkel yang sudah ada

d. Memiliki keterampilan bekerja dengan alat bantu

\section{c. Tinjauan Pustaka}

Pengelasan adalah proses penyambungan material-material menggunakan panas atau tekanan atau keduanya, dengan atau tanpa logam pengisi yang mempunyai temperatur leleh hampir sama. Filosofi dari pengelasan tersebut adalah proses memperpendek jarak atom sehingga terbentuk ikatan. Dengan kata lain pengelasan merupakan proses memposisikan atom-atom keposisi semula sehingga kembali terikat satu sama lain.

Jenis-jenis pengelasan secara proses pengelasan dapat dibedakan atas beberapa macam:
a. Las Fusi (Fusion welding)
b. Las GMAW (SMAW)
c. Las FCAW
d. Las GTAW (TIG)
e. Las PAW
f. Las SAW
g. Las Electroslag Welding (ESW)

Karena banyaknya jenis-jenis pengelasan, oleh sebab itu pada kesempatan pengabdian kepada masyarakat pada tahun 2018 ini lebih difokuskan kepada jenis pengelasan SMAW (Sheet Metal Arc Welding). SMAW adalah suatu pengelasan dimana elektroda yang dipakai bersifat consumeable (habis pakai) yang mana flux melindungi filter dari oksigen sekitar agar tidak terjadi oksidasi.

Jenis-jenis sambungan pada proses pengelasan SMAW dilakukan pada berbagai sambungan diantaranya adalah:

a. Sambungan silang

b. Sambungan T

c. Sambungan tumpul

d. Sambungan sudut

e. Sambungan sisi

f. Sambungan dengan penguat

g. Sambungan dengan tumpang Agar diperoleh hasil pengelasan SMAW yang baik, bukan cuma jenis sambungan saja yang diperhatikan, tetapi metode posisi pengelasan yang digunakan juga mempengaruhi terhadap hasil lasseperti dapat dilihat pada Gambar 2. Ada beberapa metode posisi pengelasan, yaitu:

1. Posisi pengelasan untuk sambungan Groove

- 1G (Posisi pengelasan datar)

- 2G (Posisi pengelasan horizontal)

- 3G (Posisi pengelasan vertikal)

- 4G (Posisipengelasan atas kepala atau overhead)

2. Posisi pengelasan untuk sambungan Fillet

- 1F (Posisi pengelasan datar)

- 2F (Posisi pengelasan horizontal)

- 3F ( Posisi pengelasan vertikal)

- 4F (Posisi pengelasan atas kepala atau overhead)

3. Posisi pengelasan pada pipa

- 1G (Posisi pengelasan datar pipanya dapat diputar)

- 2G ( Posisi pengelasan horizontal pipa dapat diputar) 
- 3G (Posisi pengelasan vertical pipa tidak dapat diputar)
- 4G (Posisi pengelasan pipanya miring $45^{0}$ tidak dapat diputar)

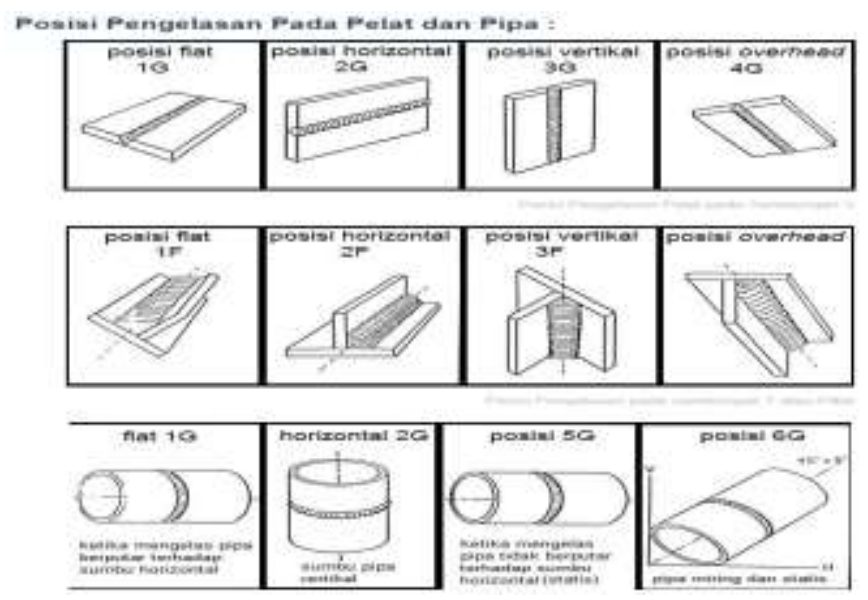

Gambar 2. Posisi Pengelasan pada Plat dan Pipa

\section{d. Keselamatan Kesehatan Kerja Pengelasan}

Keselamatan Kesehatan Kerja (K3) merupakan penting untuk setiap pekerjaan, apalagi pekerjaan pengelasan las listrik yang banyak menimbulkan bahaya, mulai dari arus listrik sampai proses pengerjaannya. Proses las yang menimbulkan cahaya bisa menyakitkan mata dan logam panas dapat melukai tubuh. K3 dimulai dari APD (alat pelindung diri) keselamatan peralatan dan keselamatan benda kerja (produksi).
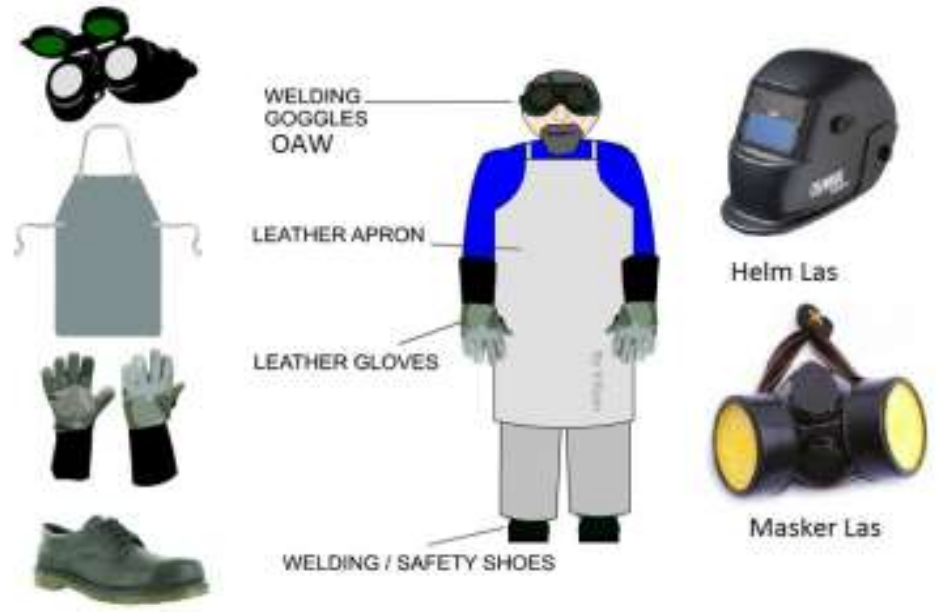

Gambar 3. Beberapa Alat Pelindung

Beberapa alat pelindung diri terdiri dari :Welding Goggles OAW, Leather Apron, Helm Las, Masker Las, Leather Gloves, Welding Safety Shoes, seperti terlihat pada Gambar 3.Keselamatan peralatan terdiri cara penggunaan dan pemakaian alat harus sesuai dengan SOP peralatan, tidak boleh salah menggunakan alat tersebut. Seperti palu terak jangan dipakai untuk memukul 
paku atau sebaliknya, begitu juga penggunaan elektroda dan amper arus pengelasan wajib sesuai dengan yang ada di keterangan elektroda.Keselamatan benda kerja (produksi) wajib dijaga mutunya sesuai pesanan agar hasil benda kerja selalu baik dan sesuai dengan pesanan.

\section{METODE PELAKSANAAN}

Rangkaian kegiatan yang akan dilakukan dapat dilihat pada Gambar 4, dan Model Lembaran Kerja dapat dilihat pada Tabel 1.

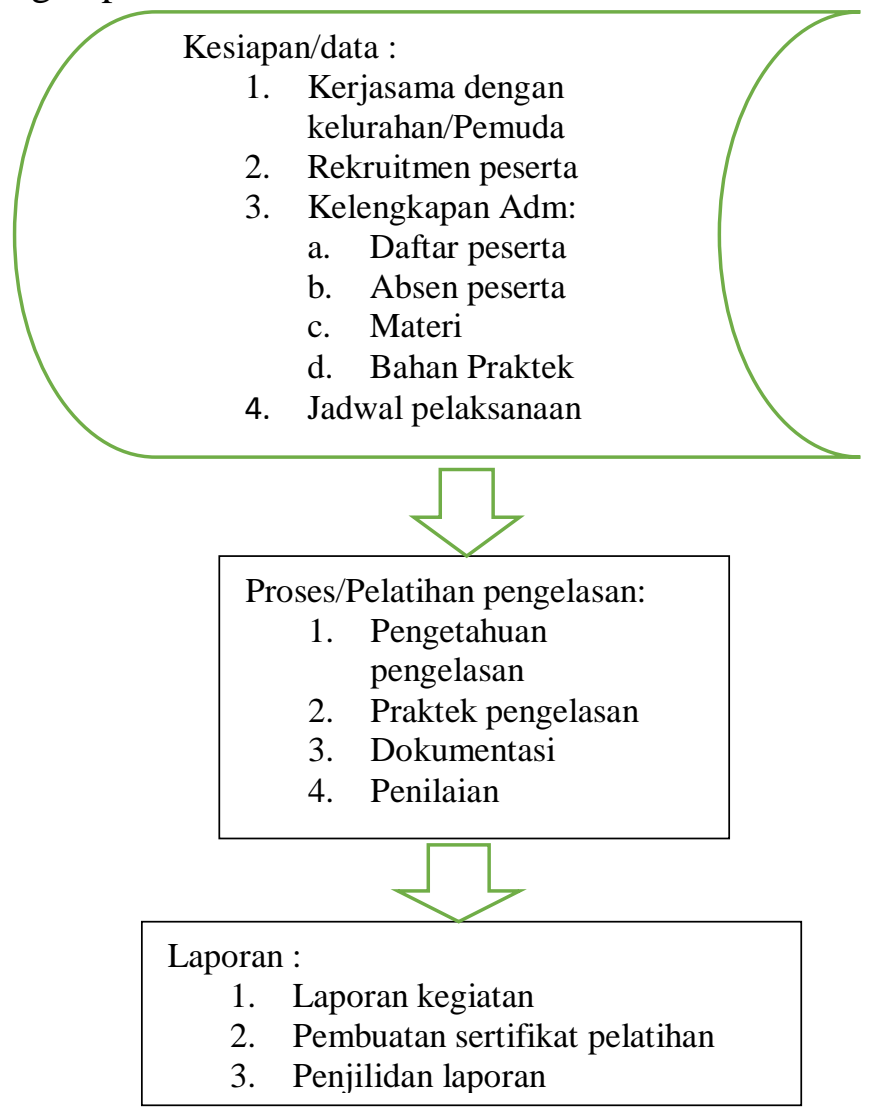

Gambar 4. Diagram Alir Kerja

Tabel 1. Model Lembaran Kerja Pengelasan

\begin{tabular}{|c|c|c|c|c|}
\hline \multirow{2}{*}{ NO } & \multirow{2}{*}{ KRITERIA UNJUK KERJA } & \multicolumn{2}{|c|}{ JENIS SAMBUNGAN } & \multirow{2}{*}{ UKURAN BAHAN } \\
\hline & & FILLET & GROOVE & \\
\hline 1 & $\begin{array}{l}\text { A. Pemotongan pelat lurus, miring, } \\
\text { melingkar luar dan dalam } \\
\text { menggunakan alat potong manual } \\
\text { didemonstrasikan sesuai SOP } \\
\text { dengan menerapkan K3. }\end{array}$ & & & 1. Plat $8 \times 50 \times 150$ \\
\hline & $\begin{array}{l}\text { B. Pemotongan pelat lurus, dan miring } \\
\text { menggunakan mesin potong gas } \\
\text { didemonstrasikan sesuai SOP } \\
\text { dengan menerapkan K3. }\end{array}$ & & & \\
\hline
\end{tabular}


2 A. Pengelasan sambungan sudut satu jalur posisi di bawah tangan dan mendatar serta sambungantumpul kampuh V dilas dua sisi (double side Vbutt)posisi di bawah tangan pada pelat dan / atau pipa baja karbon dilakukan sesuai SOP.

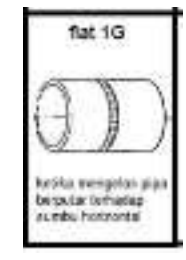

1. Pipa dia 3"

Jumlah 2 bh
A. Pengelasan sambungan sudut (fillet) jalur bertumpuk (multi layer) pada pelat posisi dibawah tangan dilakukan sesuai SOP/ WPS
B. Pengelasan sambungan tumpul (butt) dilas satu sisi (single V-butt) pada pelat posisi di bawah tangan dilakukan sesuai SOP/ WPS.

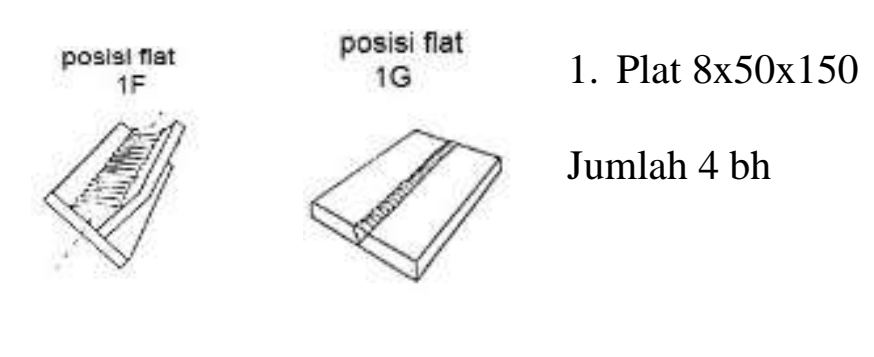

$4 \quad$ A. Pengelasan sambungan sudut (fillet) jalur bertumpuk (multi layer) pada pelat posisi mendatar dilakukan sesuai SOP/ WPS

B. Pengelasan sambungan tumpul (butt) dilas satusisi (single V-butt) pada pelat posisi mendatar dilakukan sesuai SOP/ WPS.

5 A. Pengelasan sambungan sudut (fillet) jalur bertumpuk (multi layer) pada pelat posisi mendatar dilakukan sesuai SOP/WPS

B. Pengelasan sambungan sudut (fillet)
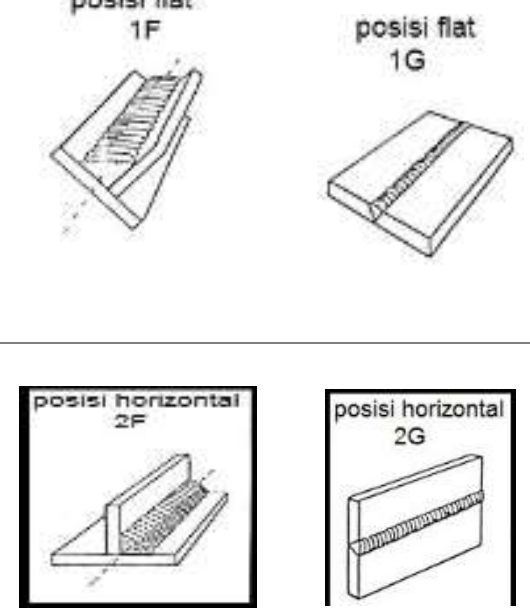

1. Plat $8 \times 50 \times 150$

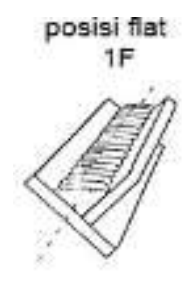

Jumlah

Plat1 bh $=4 \mathrm{~b}$ dilas satu sisi

\section{HASIL DAN PEMBAHASAN}

Hasil praktek las SMAW 2F yang dilakukan pemuda kecamatan Pauh kelurahan Koto Luar Padang, sudah menunjukan kemajuan dari tes awal yang dilakukan sebelum pelatihan. Hasil pengelasan yang didapat pada umumnya baik seperti Gambar 5.Posisi pengelasan 2F dilakukan pada posisi plat mendatar dapat dimulai dari kiri atau dari kanan seperti pada Gambar 5a. Dan pada Gambar 5b, c, dan d dapat dilihat hasil penyambungan yang dilakukan oleh siswa. Hasil yang diperoleh masih kurang rapi, karena sebagian peserta belum pernah melakukan proses pengelesan, disamping kebanyakan peserta berasal dari Sekolah Menengah Umum, jadi belum pernah mendapatkan ilmu pengelasan. 


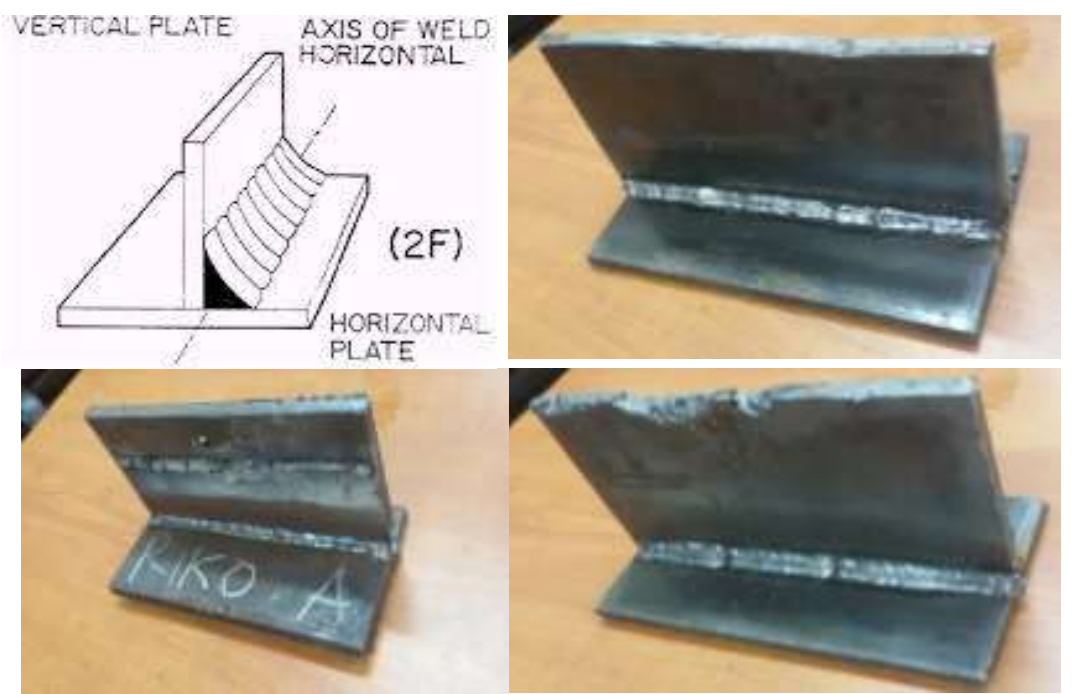

Gambar 5. a. Salah Satu Posisi Pengelasan dan b, c, d. Hasil Penyambungan

\section{Pedoman praktek kerja las SMAW2F}

Agar proses pengelasan dapat berjalan dengan lancar dan sesuai dengan standar prosedurnya, maka

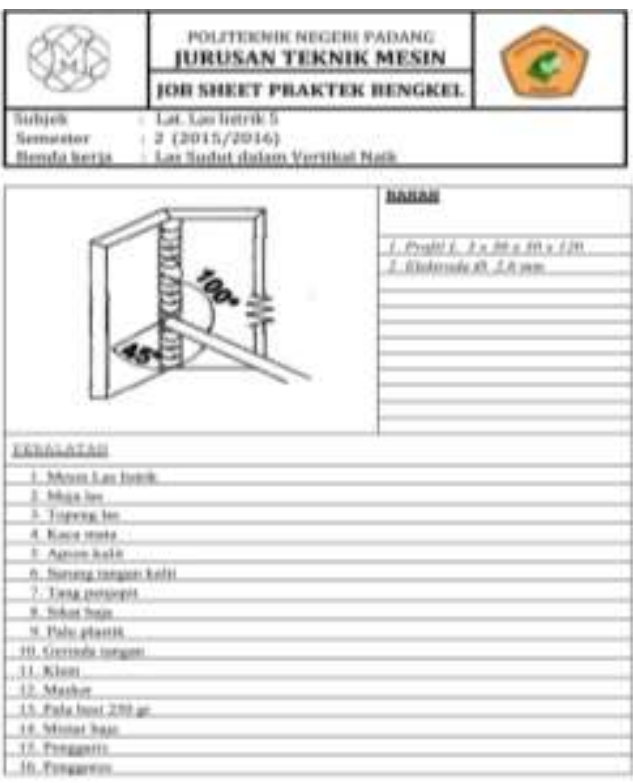

sebelum dimulai maka diharuskan semua peserta untuk membaca pedoman praktek kerja las, seperti pada Gambar 6.

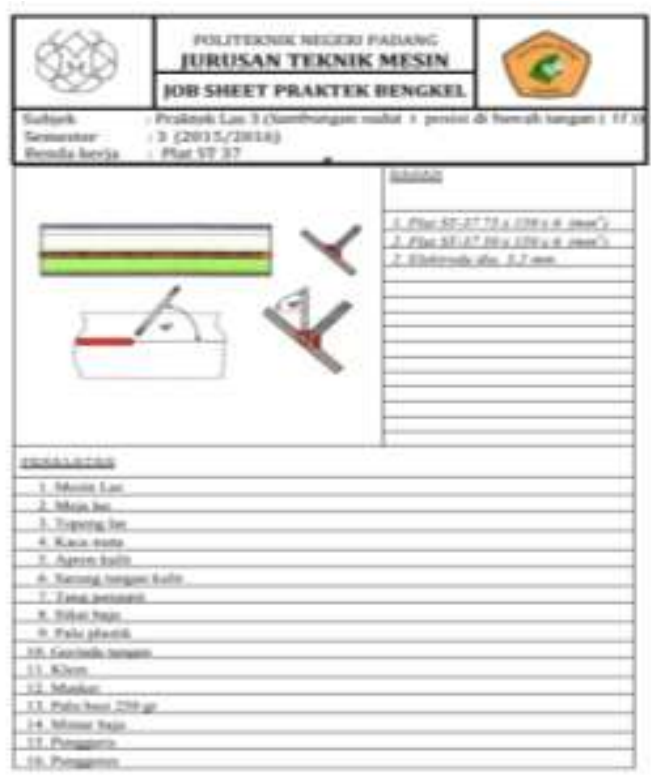

Gambar 6. Pedoman praktek kerja las SMAW2F

\section{Pemeriksaan Hasil Las}

Pemeriksaan hasil las dilakukan untuk mengetahui ketrampilan pengelasan dalam mengikuti prosedur pengelasan SMAW 2F

- Keseragaman manik manik las

- Awal las dan akhir las
- Sambungan kampuh las pada saat penggantian elektroda yang sesuai pedoman praktek kerja las SMAW2F seperti pada Gambar 6. Kriteria penilaian untuk hasil las adalah sebagai berikut:

- Tinggi rata-rata kampuh las 
- Perbedaan undercut lasan

- Lebar kampuh las

- Kampuh las bersih dari track bekas lasan

Semangat para peserta mengikuti pelatihan dapat dilihat dari kehadiran
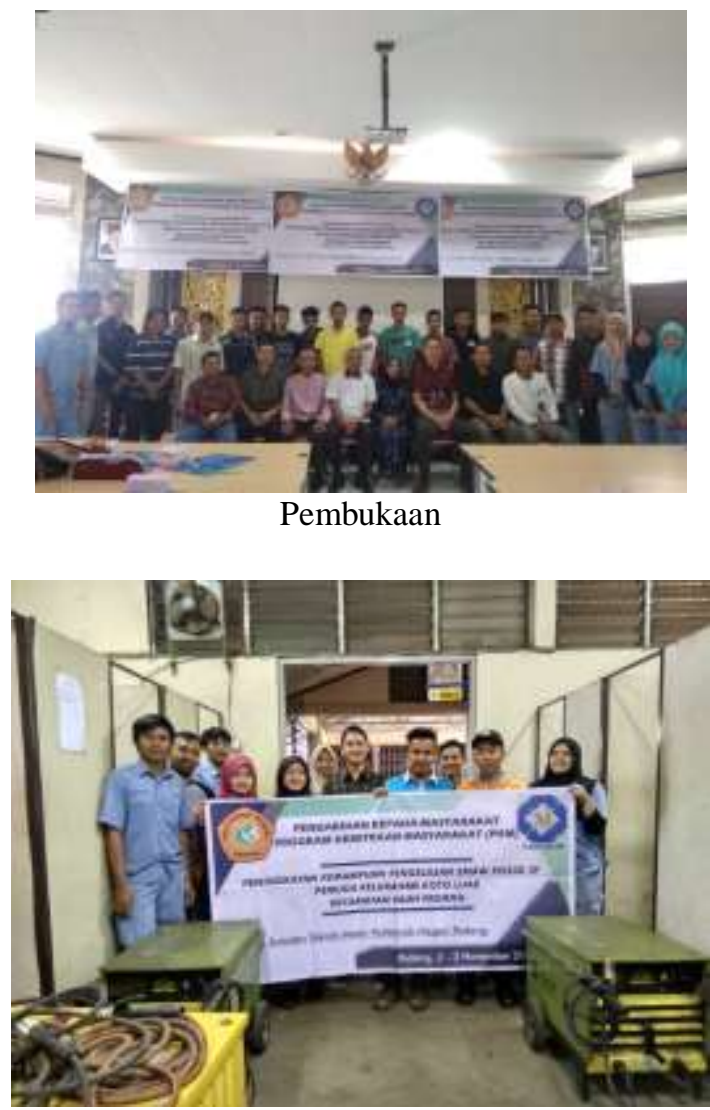

Ruang Las SMAW 2F

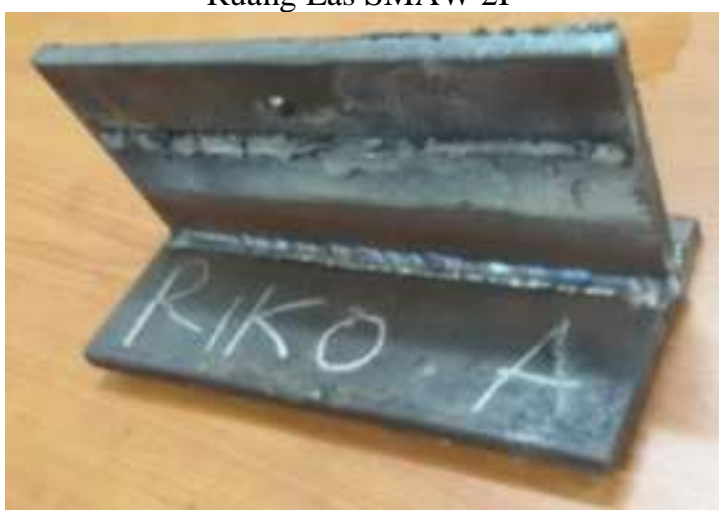

Hasil Kerja Las SMAW 2F mereka selama 2 hari melaksana instruksi dari instruktur las yang suasana pelaksanaan Pengabdian Kepada Masyarakat Pemuda Kelurahan Koto LuarKecamatan Pauh Padang Tahun 2018 dapat dilihat dokumentasinya pada Gambar 7.
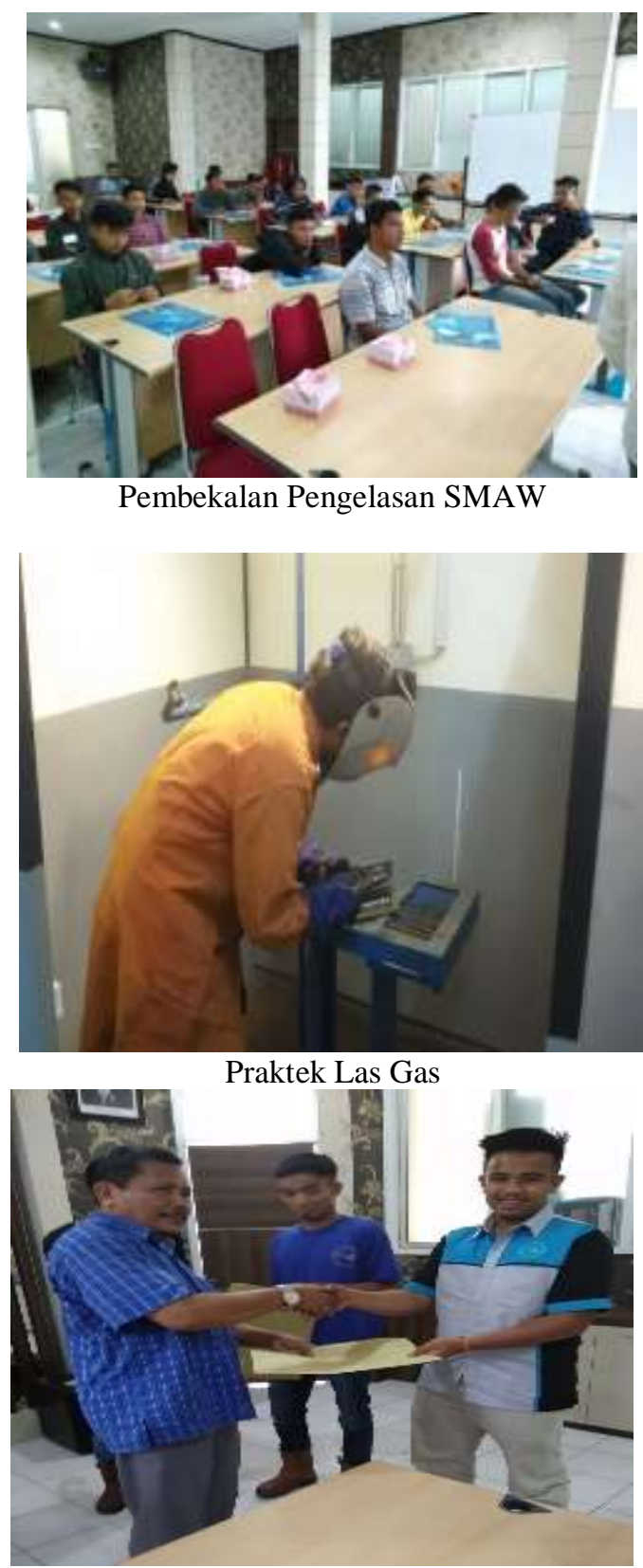

Penyerahan Sertifikat Las

Gambar 7. Pelaksanaan Pelatihan Pengelasan 


\section{PENUTUP}

Motivasi dan kemampuan 21 pemuda Koto Luar kecamatan Pauh Padang meningkat setelah dilakukan pembekalan dan pelatihan pengelasan SMAW 2F. Pelatihan yang dikuti oleh pemuda daerah tersebut berupa pembekalan dan pelaksanaan pengelasan SMAW 2F pada umumnya. Seluruh peserta pelatihan dapat mengikutinya dengan baik dan mendapatkan sertifikat pengelasan SMAW $2 \mathrm{~F}$ yang ditanda tangani direktur Politeknik Negeri Padang. Kegiatan pelatihan peningkatan pengelasan SMAW $2 \mathrm{~F}$ ini mendapat dukungan yang posistip dari ketua BPM dan Bapak Lurah, karena kegiatan ini sudah lama diinginkan oleh masyarakat karena peluang kerja untuk bidang pengelasan ada disekitar kelurahan Koto Luar.

\section{DAFTAR PUSTAKA}

Aman Suratman, Teknik Mengelas Asetilin, Brazing, dan Las Busur Listrik, Pustaka Grafika, 2001.

Awal Syahrani, Naharuddin, Muhammad Nur, Analisis Kekuatan Tarik, Kekerasan, dan Struktur Mikro pada Pengelasan SMAW Stainless Steel 312 dengan Variasi Arus Listrik, Jurnal Mekanik, vol. 9, no. 1, 814-822, 2018

Ahmad Bakhori. Perbaikan Metode Pengelasan SMAW (Shield
Metal Arc Welding pad Industri Kecil di Kota Medan, Buletin Utama Teknik, vol. 13, no. 1, 14-21, 2017.

ASM Metal Handbook, Ninth Edition, Volume 3. Stainlees Steel Welding Guide.

Harsono Wiryosumarto, Toshie

Okumura, Teknologi

Pengelasan Logam, PT Pradnya Paramita, Jakarta, 2000.

Taufiq Rochim, Teknik Bengkel 2. Proses Pemesinan PMS Bandung, HEDSP, Bandung, 1978.

Mengelas Dengan Proses Pengelasan Busur Berperisai (SMAW), Departemen Tenaga Kerja dan Transmigrasi RI Direktorat Jenderal Pembinaan dan Produktivitas, 2007.

- Modul Pelatihan Berbasis Kompetensi Sub Sektor Industri Barang dan Logam Sub Bidang Pengelas SMAW, Departemen Tenaga Kerja dan Transmigrasi RI Direktorat Jenderal Pembinaan dan Produktivitas, 2005.

- Training Juru Las Kelas 1, 2\& 3 Sertfikasi Kemnaker, HSP Academy, 2005.

Teknik Las SMAW, Kementerian Pendidikan dan Kebudayaan Republik Indonesia, 2013. 